Author Accepted Version. Final version published as: Temple, J. B., \& Williams, R. (2018). Multiple health conditions and barriers to healthcare among older Australians: prevalence, reasons and types of barriers. Australian Journal of Primary Health, 24(1), 82-89.

\title{
Multiple Health Conditions and Barriers to Health Care Among Older Australians: Prevalence, Reasons and Types of Barriers
}

\begin{abstract}
Accompanying population ageing is an increase in the number of older Australians living with multiple health conditions and disabilities (AIHW 2014). We seek to examine the barriers to accessing health care faced by this growing group of older Australians. Utilising the 2014 ABS General Social Survey, we find six per cent of respondents aged 50 years and over reported experiencing a barrier to accessing health care within the previous 12 months. Those with multiple health conditions are at a considerably higher risk of experiencing a barrier to health care $(21 \%$ of those with 4 or more disabilities reported experiencing a barrier to health care) compared with people with no or fewer health conditions, and this risk persists once wide ranging control variables are included. Long waiting times or unavailability of appointments (43\%) were the main type of barriers to accessing health care, followed by cost $(23 \%)$. The points of care barriers were most prevalent in regard to accessing GPs and specialists. However, people with multiple health conditions also had greater points of care access difficulties in the hospital sector relative to those with no or fewer conditions. Those who had experienced a barrier were more likely to have low levels of trust in the health care system compared with people who had no experience of barriers to health care, and were also more likely to have a perception of experiencing discrimination or unfair treatment in a health care setting.
\end{abstract}




\section{Summary Statement}

What is known about the topic?

- Recent Australian studies have shown that people living with multiple health conditions, or co-morbidities, have significant out-of-pocket health care expenses. This financial burden has been shown to be a barrier to seeking health-care services.

$\underline{\text { What does this paper add? }}$

- Older people with multiple health conditions were (i) more likely to experience barriers to health care than those without multiple health conditions, (ii) the main types of barriers to accessing health care were not only related to cost, but also waiting times, availability of appointments and issues of geographic access and (iii) these barriers were experienced across all levels of the health care system including in regard to accessing GPs and specialists as well as accessing care in the hospital sector.

The author's declare no conflicts of interest. 


\section{Multiple Disabilities and Barriers to Health Care Among Older Australians: Prevalence, Reasons and Types of Barriers}

\section{Introduction}

Australia has a comprehensive universal health care system, with individuals funding 17\% of private health care costs in 2015 (AIHW 2016). Through the Medicare Benefits Schedule (MBS), the Australian Health Care Agreements (AHCA) as well as the Pharmaceutical Benefits Scheme (PBS), the Federal government funds the majority of expenses relating to hospitals, doctors and optometrist services, as well as pharmaceuticals. Some commentators have suggested that this combination of policies has enabled relatively unencumbered health care access for older Australians (McIntosh \& Phillips 2003).

However, with increasing longevity in Australia, multiple health conditions, also referred to as multiple morbidities or co-morbidities, are becoming more prevalent in the older population (Barnett 2012; Boyd 2005). Health care groups have stated in government submissions that demand for co-ordinated care by people with multiple conditions is not being met (Metherell 2011). Recent studies have found that even with considerable government subsidies, those with multiple health conditions can face very high out-of-pocket health care costs (relative to income) and that many of these people are at risk of financial stress (Kemp et al. 2013; Carpenter et al. 2015; McRae et al. 2013). This has been shown to contribute to the skipping of treatment all together (Callander et al, 2017). 
Motivated by these recent studies, we sought to answer three questions with respect to older Australians with multiple health conditions: (1) What are the most prevalent types of barriers? (2) How prevalent are these barriers to accessing health care?, and (3) At what point of care in the Australian health care setting are barriers more commonly experienced?

\section{Methods}

Data used in this study are from the 2014 General Social Survey (GSS) conducted by the Australian Bureau of Statistics (ABS) between March and June 2014. Of an initial sample of 18,574 private dwellings, 16,145 dwellings were used due to issues of scope or uninhabited dwellings. In total, $80 \%$ fully responded, yielding a sample of 12,932 people aged 15 years and over. From the full survey, we utilise a sample of 6,012 respondents aged 50 years and over to model the prevalence of barriers to accessing health care. As the occurrence of multiple health conditions significantly increases with age, we limit our population to those aged 50 years and over.

Using a face-to-face interview along with prompt cards, the ABS collected information on a range of health conditions and disabilities, and access to health care. For the modelling herein, the dependent variable, barrier to health care, is coded ' 1 ' if an individual reported they needed health care, but could not access it within the last 12 months, and is coded ' 0 ' if they did not experience this barrier.

Utilising prompt cards, ABS interviewers sought further information on the aspects of the barrier. Respondents were asked: 'Thinking of the most recent time you could not obtain health care, what type of health care was it?' A prompt card was shown to indicate (1) doctor/GP, (2) hospital, (3) medical specialist, 
chemist/pharmacist/prescription, (5) dental professional, or (6) other health professional. ABS interviewers further prompted the respondents: 'Thinking of the most recent time you could not obtain health care, what was the main reason?' A prompt card was shown to indicate (1) no service available in area at time needed, (2) waiting time too long / no appointments, (3) cost of service and (4) a range of 'other' items, which were later aggregated by the ABS.

Although our primary interest is on the effects of multiple health conditions upon barriers to accessing health care, we utilised a number of measurements of specific and multiple conditions. These included counts of types of disabling conditions, long-term health conditions and specific disability types.

Importantly, the GSS provided a number of other measures on health care experiences. Two variables included levels of trust and measures of discrimination experienced within the health care system. These variables have not been included in the regressions as the direction of association is unclear. For example, is trust low due to experiencing a barrier to health care or do respondents with low levels of trust avoid health care all together? The GSS included a question asking respondents "How strongly do you agree or disagree that the healthcare system can be trusted?" Respondents answered on a five point scale from strongly agree to strongly disagree.

Another measure available was the perceived experience of health care discrimination. Respondents were asked, 'In the past 12 months, do you feel that you have experienced discrimination or have been treated unfairly by others?' Those who responded 'yes', were then asked about the 'places or situations' where they felt they had been 
discriminated against. A prompt card was then shown with 15 options, one being 'dealing with people involved in health care'.

To analyse the role of multiple health conditions upon the propensity to be at risk of health care access barriers, it is important to control for other factors associated with health care access. For example, are the health condition effects strong because of the declining health care barrier propensity with age? To model the association between health conditions and health care access, we estimate logistic regression models using Stata via the ABS Remote Access Data Laboratory (RADL). Extensive control variables are included, consisting of age, country of birth, marital status, region of residence, gender, education, transport access and household income.

To contextualize the regression results, we present descriptive data on the prevalence and types of barriers and the point of barriers at which they occur. Significant differences between demographic groups are ascertained using WALD tests of proportions with a critical $\mathrm{p}$ value of 0.05 .

\section{Results}

Results from our analyses showed that about $7 \%$ of people aged under 50 years $(95 \%$ $\mathrm{CI}=6.3,7.5)$ and about $6 \%$ of people aged 50 years and over $(95 \% \mathrm{CI}=5.2,6.3)$ experienced a barrier to accessing health care in the last 12 months. Of the population aged 50 years and over, there are considerable differences in the prevalence of health care barriers by disability and health conditions, regardless of the measure used (Table 1). Compared to those with no disability, respondents with multiple disabilities are at a 
substantially higher risk of facing access barriers to health care. About $11 \%$ of respondents with 3 or more disability types and $21 \%$ of those with 4 or more disability types cited access barriers to health care when compared to just $2.4 \%$ of respondents with no health conditions. This finding is broadly replicated when using the number of long-term conditions as a measure of co-morbidity, but to a lesser degree. For example, about $12 \%$ of those with 4 or more long-term health conditions cited experiencing a health care barrier within the previous 12 months.

\section{[TABLE 1]}

When focusing on the type of conditions, it is clear that specific conditions are associated with a higher likelihood of experiencing a barrier to accessing health care. The proportions of respondents experiencing a barrier are particularly high for those with a psychological disability (19.5\%), those with a disability due to head injury, stroke or brain damage (18\%), or an intellectual disability $(14 \%)$.

Among the control variables, the propensity to experience a health care barrier decreases with increasing age and increasing household income. However, those who have never married, or are divorced, are more likely to experience a health care barrier relative to people who are married/partnered. Having a driver's licence, but no access to a motor vehicle is also associated with experiencing a barrier to health care. Interestingly, there are no reported differences in experienced health care barriers by country of birth, region of residence, sex or level of education [1]. 
Three logistic regression models were used to investigate the association between health conditions and health care (Table 2). Model 1 recorded counts of disabilities, model 2 used counts of long-term health conditions and model 3 introduced specific health condition types into the model. These variables cannot be included in the same model due to multicollinearity, resulting in unstable parameter estimates on health conditions.

\section{[TABLE 2]}

Once controls were included for a range of demographic and economic factors, differences in the propensity to experience health care barriers persisted. Those with 4 or more disabilities were at a 10 fold risk of experiencing a health care barrier compared to those with no health condition $(\mathrm{OR}=10.3 \mathrm{p}<0.01)$. This risk was 4 and 5 fold for those with $2(\mathrm{OR}=4.3 \mathrm{p}<0.01)$ or $3(\mathrm{OR}=5.6 \mathrm{p}<0.01)$ disabilities. This grading effect with respect to total disabilities was also reflected in model 2 using total long-term health conditions. Those with 4 or more long-term health conditions were at an almost 6 fold risk of experiencing a health care barrier relative to those with no long-term health condition $(\mathrm{OR}=5.8 \mathrm{p}<0.01)$.

Importantly, there were also differences in health care access by type of condition. Respondents with a psychological $(\mathrm{OR}=2.13 \mathrm{p}<0.01)$ or physical disability $(\mathrm{OR}=2.56$ $\mathrm{p}<0.01)$ were at a considerably higher risk of experiencing health care barriers relative to those with no health condition. 
Apart from acting as important statistical controls, the demographic and economic factors were also of substantive interest in themselves. Broadly supporting the bivariate results, health care access barriers tend to decrease with increasing age and increasing income. They also appeared to be relatively higher for those who have never been married and marginally so for those living outside of capital cities. Supporting the underlying model specification, the directions and patterns of significance were relatively consistent between all three models.

\section{[TABLE 3]}

Using the GSS data, we also examined the type of barrier experienced by respondents. Of the 346 respondents aged 50 years and over in this sample who experienced a barrier to accessing health care, about $43 \%$ cited waiting time or unavailability of appointments as the primary reason (Table 3$)$. This was followed by cost $(23 \%)$, other considerations $(18 \%)$ and service availability in the area (16\%). Those with 2 or more disabilities were more likely to cite 'service availability in the area' as a barrier when compared to those with no or 1 condition type. Of the specific condition types, those with a psychological condition were less likely to cite waiting time but more likely to cite cost as the key reason for not accessing health care.

There were also strong variations in the point of care of barrier faced (Table 4). In about equal measure, $30 \%$ of respondents cited difficulty accessing a doctor/GP or a health care specialist. A further $15 \%$ cited access to dental professionals or hospitals as being their concern. About $8 \%$ of respondents reported inaccessibility to other health professionals and only $1 \%$ of respondents had difficulty filling a script at a pharmacy. 
There were also variations in the point of care barriers by health conditions. Compared to respondents with no condition, people experiencing any or multiple conditions were less likely to cite access to a GP and more likely to cite access to a hospital or other health professionals as being problematic. Not surprisingly, people with a psychological disability reported having greater difficulty accessing care from other health professionals (including psychologists) compared to the general population.

\section{[TABLE 4]}

Respondents who reported having experienced a barrier to health care were more likely to cite low levels of trust in the Australian health care system. For example, $44 \%$ of those who had faced a health care barrier either disagreed or strongly disagreed with the above trust statement compared to $17 \%$ of respondents who had not experienced a barrier to health care (Table 5).

Noting the limitations of sample size, respondents who indicated experiencing a barrier to health care were also more likely to report having experienced discrimination in a health care setting. About $10 \%$ of respondents who reported experiencing a barrier to health care, cited they had experienced discrimination or had been treated unfairly 'dealing with people involved in health care' (Table 5). Among respondents who had not experienced a barrier, the figure was negligible (around 1\% of the 50 years and older population). 


\section{Discussion}

Approximately $6 \%$ of the population aged 50 years and over reported experiencing a barrier to accessing health care within the previous 12 months. However, those with multiple health conditions were considerably more likely to experience a barrier when accessing health care. Controlling for a wide range of demographic and economic characteristics, it was found respondents with 4 or more disabilities were 10 times more likely to experience a barrier to accessing health care, than those with no health condition. Even those with a moderate number of disabilities (2 or 3), were between 4 and 6 times more likely to experience a barrier to accessing health care. These results were broadly replicated in a model of total long-term health conditions.

These findings are important because with improvements to longevity and an increasing number of older people, there is a higher likelihood of multiple health conditions arising within the population (AIHW 2014). As the prevalence of multiple conditions rises, so too does polypharmacy and the likelihood of adverse drug effects, compounding the need for further access to the health care system. Failure to adequately address access to health care at the preventative and primary care level could result in long-term implications for both individuals and government. For example, given the propensity for unattended health conditions to escalate in severity, this may contribute to poorer quality of life, unnecessary hospitalisations and eventually placing greater strain on acute care systems (e.g. Paddison et al. 2015; AHIW 2014; Wolff et al. 2002).

Individuals with a psychological or physical disability were also found to be more than twice as likely to experience a barrier to accessing health care compared to respondents with no condition. This finding is important as people with psychological conditions 
are more likely to concurrently experience chronic illnesses, with an earlier onset of illness and greater premature mortality than the general population (AIHW 2010; AHPC 2016). In addition, the prevalence of mental ill-health in Australia is substantial within community-dwelling older Australians and the majority with poor mental health do not consult specialist mental health services (Trollor et al. 2007). The problem of accessing care for those with psychological conditions was also likely exacerbated by low detection rates by primary health workers (ABS 2007). In addition, we found that those with a diagnosed psychological condition were also more likely to cite cost as a barrier to accessing care.

Although not the key focus of this study, a number of demographic and economic factors were found to be associated with access difficulties. Not surprisingly, increasing levels of household income were associated with decreasing propensities to experience a barrier to accessing health care. This finding is consistent with Australian studies showing levels of financial stress experienced by lower income households in meeting ongoing health care costs (Kemp et al. 2013; Carpenter et al. 2015).

Notably, access problems were also found to decline with increasing age, reflecting several possible reasons. Firstly, individuals who are 65 years and older or 50 years and older for Aboriginal and Torres Strait Islander people, have access to and are more likely to be covered by the Home and Community Care program (HACC). Within this program they are able to access services such as nursing care, allied health services, domestic assistance and personal care thereby offsetting some of the personal attributes that may make access to health care difficult. Secondly, there is a possibility of a selectivity effect in survival occurring in these cross sectional data. As wealthier 
individuals are more likely to exhibit higher survival prospects relative to their financially disadvantaged peers; in cross sectional data we may be observing these individuals (Disney 1996). As shown in the modelling, higher levels of income are shown to strongly mitigate against barriers to accessing health care, thus biasing the age based results we observe.

These analyses also showed variations in the reasons and types of barriers to health care experienced by older Australians. Supporting previous Australian studies showing health care affordability problems, we show that about $23 \%$ of older Australians who faced a barrier, did not access care specifically due to cost. Of specific health condition types, respondents with a psychological disability were more likely to cite an access barrier (33\%). This finding may reflect the differential way psychology services are accessed and funded in Australia, when compared to standard GP services.

Although the cost of health care was important, higher proportions of older Australians cited long waiting times or unavailability of appointments as the primary types of barriers to health care (43\%). A further $16 \%$ cited services were not available in their local area as the key type of barrier. For respondents with multiple conditions, this later concern was particularly prevalent relative to those with no health condition. This is likely reflective of the greater unmet need for hospital services for those with multiple conditions that we observe in these data.

The majority of respondents aged 50 years and over who experienced a point of care barrier to accessing health care, were more likely to nominate difficulties regarding accessing a GP or specialist services as the main point of care barriers experienced. 
Types of barriers such as experiencing long waiting times, and unavailability of appointments, can demotivate people to attend to their current illnesses as well as those they may develop in the future. This demotivation effect is important as we observe that respondents who experienced a barrier to accessing health care had lower overall levels of trust in the health care system and a sizeable minority (around 10\%) cited experiencing discrimination in the health care system. This potentially creates a selfperpetuating scenario whereby experiencing discrimination can have a detrimental effect on psychological health by increasing stress and anxiety, requiring the individual to access further health care (Kelaher et al. 2008; Otiniano \& Gee 2012). More generally, these findings pose further issues for individuals' re-engagement into effective health care treatment. The longer an adverse health condition is untreated, the more likely it will escalate into a severe illness, resulting in a more significant physical and/or psychological burden to the individual and financial burden to both the individual and the overall health care system (e.g. Keshavan et al. 2003; Altamura et al. 2009).

In interpreting the results from this study, it is important to note the limitations. Firstly, the data are cross sectional and the measures of access to health care may be subject to recall bias. If longitudinal data were available, the prevalence of experiencing a barrier to care may be higher. Secondly, older people with multiple health conditions are more likely to have frequent contact with the health care system compared with healthy older people with no or fewer health conditions. Therefore, those experiencing multiple health conditions are at more risk of experiencing barrier/s and/or negative experiences. The GSS survey instrument does not enable us to isolate those who did not experience 
a barrier to care simply because they did not need to access health services. Excluding this group from the analysis would result in much higher proportions of the over 50 population reporting a barrier to care. This study and future analysis would benefit by having access to the number of total health care interactions respondents have had within the previous 12 month period.

Noting these limitations, although the prevalence of barriers to health care among community dwelling older Australians is generally low (around 6\% in the previous 12 months), those with multiple health conditions were at a considerably higher risk of inability to access health care. Point of care barriers were most prevalent in regard to accessing GPs and specialists within the broader population. However, people with multiple conditions reported greater difficulties in accessing hospitals relative to those with no or fewer health conditions. Although cost was a major barrier, simply accessing health care without excessive waiting times or ability to book an appointment at all was noted as the primary type of barrier for many older Australians including those with multiple health conditions.

As population ageing results in increased numbers of older Australians with multiple health conditions, access problems may become heightened at a population health level. The consequences of not obtaining timely care are considerable for both the individual and the greater health system. This study suggests that one important future direction of research in this area is on co-ordinated care approaches that are targeted towards older Australians with multiple health conditions. Specifically, given population ageing and an increasing number of older persons with comorbidities, how 
we can achieve a more integrated, comprehensive, and holistic response to the barriers to accessing the health care system in Australia?

\section{Conflicts of Interest}

None exist.

\section{Notes}

[1] Alternative measures of these variables and additional variables were also considered including, English language proficiency, main language spoken at home, State of residence, time in current dwelling, source of income and multiple interaction effects- but the differences in barriers to health care were all negligible.

\section{References}

ABS. Microdata: General Social Survey, Australia, 2014. 2015. ABS Cat. No. 4159.0.30.004, Australian Bureau of Statistics: Canberra.

ABS. National Survey of Mental Health and Wellbeing, Summary of Results, 2007. 2008. ABS Cat. No. 4326.0, Australian Bureau of Statistics: Canberra.

Altamura, A., Berlin, H., Bassetti, R., Duration of untreated illness and suicide in bipolar disorder: a naturalistic study, European Archives of Psychiatry and Clinical Neuroscience 2010, 260:385-391 
Australian Health Policy Collaboration (AHPC) 2016, The costs and impacts of a deadly combination: Serious mental illness with concurrent chronic disease, Policy Issues Paper 01, 2016.

AIHW. Chronic disease comorbidity 2014, Australian Institute of Health and Welfare: Canberra

AIHW. Health Expenditure Australia 2014-15. 2016. Health and Welfare Expenditure Series No. 57, Australian Institute of Health and Welfare: Canberra.

Barnett, K., Mercer, S., Norbury, M., Watt, G., Wyke, S., Guthrie, B., Epidemiology of multimorbidity and implications for health care, research and medical education: a cross-sectional study, The Lancet, 2012, 380, 37-43.

Boyd, C., Darer, J., Boult, C., Fried, L., Boult, L., Wu, A., Clinical Practice Guidelines and quality of care for older patients with multiple comorbid diseases: Implications for pay performance, Journal of the American Medical Association 2005, 294:6 716-724.

Callander, E., Corscadden, L., and Levesque, J., Out-of-pocket healthcare expenditure and chronic disease - do Australians forgo care because of the cost? Australian Journal of Primary Health 2017; 23: 15-22.

Carpenter, A., Mofizul Islam, M., Yen, L., McRae, I., Affordability of out-of-pocket health care expenses among older Australians, Health Policy 2015 
Disney, R. Can We Afford to Grow Older? A Perspective on the Economics of Aging. London: MIT Press, 1996.

Kelaher, M., Paul, S., Lambert, H., Ahmad, W., Paradies, Y., \& Davey Smith, G., 'Discrimination and health in an English study', Social Science of Medicine, 2008, $66: 7,1627-36$.

Kemp, A., Preen, D., Glover, J., Semmens, J., Roughead, E., Impact of cost of medicines for chronic conditions on low income households in Australia. Journal of Health Services Research and Policy 2013; 18: 21-27

Keshavan, M., Haas, G., Miewald, J., Montrose, D., Reddy, R., Schooler, N., and Sweeney, J., Prolonged untreated illness duration from prodromal onset predicts outcome in first episode psychoses, Schizophrenia Bulletin, 2003; 9:4 757-769

McRae, I., Yen, L., Jeon, Y., Herarth, P., Multimorbidity is associated with higher out-of-pocket spending: a study of older Australians with multiple chronic conditions. Australian Journal of Primary Health 2013; 19: 144

McIntosh, G., Phillips, J., Caring for the Elderly: An Overview of Aged Care Support and Services. 2003 Ebrief, Department of the Parliamentary Library: Canberra

Metherell, M., Health Care for Elderly Inadequate. Sydney Morning Herald $27 / 12 / 2011$ 
Otiniano, AD., and Gee, GC., 'Self-reported discrimination and health-related quality of life among Whites, Blacks, Mexicans and Central Americans', Journal of Immigration Minor Health, 2012, 14:2, 189-97.

Paddison, C., Saunders, C., Abel, G., Payne, R., Campbell, J., Roland, M., Why do patients with multimorbidity in England report worse experiences in Primary Care? Evidence from the General Practices Patient Survey, British Medical Journal Open $2015,5: 3,, 1-10$

Trollor, J., Anderson, T., Sachdev, P., Brodaty, H., and Andrews, G. Prevalence of Mental Disorders in the Elderly: The Australian National Mental Health and WellBeing Survey, American Journal of Geriatric Psychiatry 2007;15:6, 455-466.

Wolff, J., Starfield, B., Andersen, G., Prevalence, Expenditures and Complications of multiple chronic conditions in the elderly, Archives of Internal Medicine, 2002162 $2269-2276$ 
Table 1: Prevalence of Experiencing a Health Care Barrier, 2014

\begin{tabular}{ll}
\hline & Percentage \\
Experienced \\
Barrier to Health Care
\end{tabular}

\section{Health Conditions}

Total Disabilities

4+

02936

$1 \quad 825$

21268

$3 \quad 691$

$4+\quad 292$

Total Long Term Conditions

$4+$

1504

1419

1098

766

1225

2.4

4.4

8.2

10.9

20.9

0

1

2

3

$4+$

Disability Type

Sight, hearing, speech

1617

Physical

2291

Intellectual

222

Psychological

497

Head injury, stroke or brain damage

169

Other Disability

1908

2.4

3.2

5.7

6.8

12.2

8.2

10.6

14

19.5

17.8

$10.8 * * *$

\section{Control Variables}

Age

$50-592062$

60-69 1952

$70+$

1998

Country of Birth

Australia $\quad 4184$

MES 843

985

8.8

5.7

2.7

Other

5.8

5.5

5.9

Marital Status

Married

2905

Never Married

690

Widowed

1008

Divorced

1149

260

4.4

9.4

4.5

Separated

8.1

6.2

Region

Capital City

2886

Balance

3126

5.3

6.2

Sex 


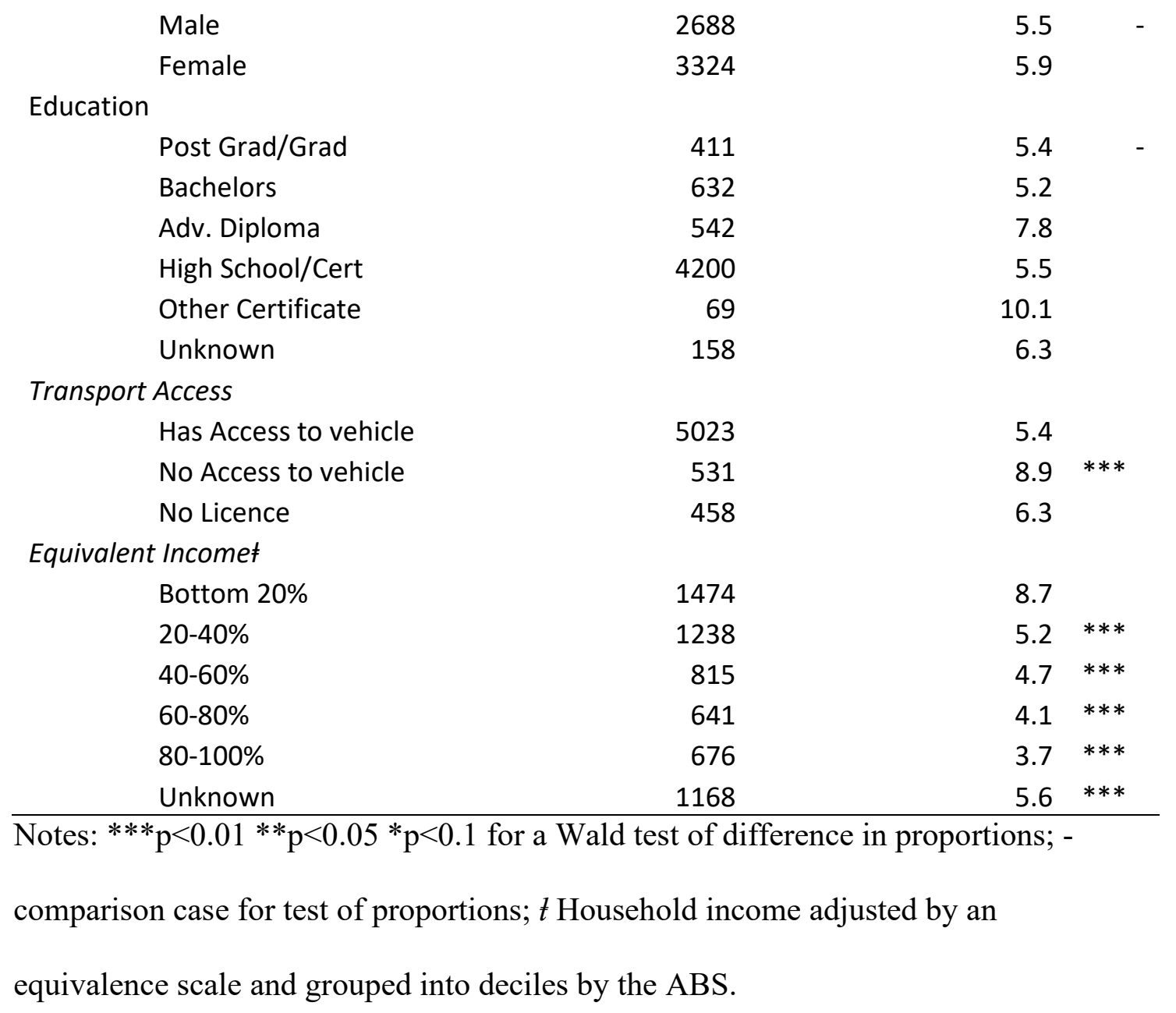

TABLES $2-5$ OVERLEAF 
Table 2: Odds Ratios of Barriers to Health Care - Multiple Disabilities (Model 1), Multiple Long-Term Health Conditions (Model 2) and Disability Type (Model 3)

\begin{tabular}{|c|c|c|c|c|c|c|c|c|}
\hline \multicolumn{3}{|l|}{ Model 1} & \multicolumn{3}{|l|}{ Model 2} & \multicolumn{3}{|l|}{ Model 3} \\
\hline & \multicolumn{2}{|l|}{ OR } & \multicolumn{3}{|c|}{ OR } & & \multicolumn{2}{|c|}{ DR } \\
\hline \multicolumn{3}{|l|}{ Total Disabilities } & \multicolumn{3}{|c|}{ Total Long Term Conditions } & \multicolumn{3}{|l|}{ Disability Type } \\
\hline 0 & & - & 0 & & - & Sight, hearing, speech & 1.27 & * \\
\hline 1 & 2.11 & $* * *$ & 1 & 1.51 & $*$ & Physical & 2.56 & $* * *$ \\
\hline 2 & 4.29 & $* * *$ & 2 & 2.82 & $* * *$ & Intellectual & 0.87 & \\
\hline 3 & 5.61 & $* * *$ & 3 & 3.33 & $* * *$ & Psychological & 2.13 & $* * *$ \\
\hline $4+$ & 10.34 & $* * *$ & $4+$ & 5.80 & $* * *$ & $\begin{array}{l}\text { Head injury, stroke or brain } \\
\text { damage }\end{array}$ & 1.39 & \\
\hline & & & & & & Other Disability & 1.64 & $* * *$ \\
\hline \multicolumn{9}{|l|}{ CONTROLS } \\
\hline \multicolumn{9}{|l|}{ Age } \\
\hline $50-59$ & & - & & & - & & & - \\
\hline $60-69$ & 0.54 & $* * *$ & & 0.53 & $* * *$ & & 0.55 & $* * *$ \\
\hline $70+$ & 0.19 & $* * *$ & & 0.19 & $* * *$ & & 0.21 & $* * *$ \\
\hline \multicolumn{9}{|l|}{ Country of Birth } \\
\hline Australia & & - & & & - & & & - \\
\hline MES & 1.13 & & & 1.10 & & & 1.13 & \\
\hline Other & 1.14 & & & 1.20 & & & 1.12 & \\
\hline \multicolumn{9}{|l|}{ Marital Status } \\
\hline Married & & - & & & - & & & - \\
\hline Never Married & 1.47 & $* *$ & & 1.50 & $* *$ & & 1.46 & $* *$ \\
\hline Widowed & 1.23 & & & 1.30 & & & 1.22 & \\
\hline
\end{tabular}




\begin{tabular}{|c|c|c|c|c|c|c|}
\hline Divorced & 1.29 & $*$ & 1.30 & $*$ & 1.25 & \\
\hline Separated & 0.92 & & 0.90 & & 0.94 & \\
\hline \multicolumn{7}{|l|}{ Region } \\
\hline Capital City & & - & & - & & - \\
\hline Balance & 1.22 & $*$ & 1.20 & $*$ & 1.25 & $*$ \\
\hline \multicolumn{7}{|l|}{ Sex } \\
\hline Male & & - & & - & & - \\
\hline Female & 1.17 & & 0.94 & & 1.08 & \\
\hline \multicolumn{7}{|l|}{ Education } \\
\hline Post Grad/Grad & & - & & - & & - \\
\hline Bachelors & 0.85 & & 0.90 & & 0.84 & \\
\hline $\begin{array}{l}\text { Adv. Diploma } \\
\text { High }\end{array}$ & 1.25 & & 1.20 & & 1.27 & \\
\hline $\begin{array}{l}\text { School/Cert } \\
\text { Other }\end{array}$ & 0.79 & & 0.80 & & 0.79 & \\
\hline Certificate & 1.29 & & 1.30 & & 1.26 & \\
\hline Unknown & 1.10 & & 0.90 & & 1.10 & \\
\hline \multicolumn{7}{|l|}{ Transport Access } \\
\hline Has Access & & - & & - & & - \\
\hline No Access & 1.09 & & 1.30 & & 1.12 & \\
\hline No Licence & 0.89 & & 1.10 & & 0.96 & \\
\hline \multicolumn{7}{|l|}{ Equivalent Income } \\
\hline Bottom 20\% & & - & & - & & - \\
\hline $20-40 \%$ & 0.72 & $* *$ & 0.73 & $* *$ & 0.72 & $*$ \\
\hline $40-60 \%$ & 0.63 & $* *$ & 0.54 & $* *$ & 0.63 & $* *$ \\
\hline $60-80 \%$ & 0.50 & $* *$ & 0.43 & $* * *$ & 0.52 & $* * *$ \\
\hline $80-100 \%$ & 0.47 & $* *$ & 0.38 & $* * *$ & 0.48 & $* * *$ \\
\hline Unknown & 0.74 & * & 0.70 & $* *$ & 0.75 & * \\
\hline
\end{tabular}


Notes: $* * * \mathrm{p}<0.01 * * \mathrm{p}<0.05 * \mathrm{p}<0.1$; - comparison group for odds ratios; $t$ Household income adjusted by an equivalence scale and grouped into deciles by the ABS. 
Table 3: Type of Barrier - Multiple Disabilities, Multiple Long-Term Health Conditions and Disability Type.

\begin{tabular}{|c|c|c|c|c|c|c|c|c|c|c|}
\hline & & $n=$ & $\begin{array}{l}\text { Service } \\
\text { Availability }\end{array}$ & & $\begin{array}{l}\text { Waiting Time or } \\
\text { No Appointment }\end{array}$ & & Cost & & Other & \\
\hline \multicolumn{11}{|l|}{ Disability Factors } \\
\hline \multicolumn{11}{|l|}{ Total Disabilities } \\
\hline & 0 & 70 & 8.6 & - & 48.6 & - & 28.6 & - & 14.3 & - \\
\hline & 1 & 36 & 11.1 & & 63.9 & & 13.9 & $*$ & 11.1 & \\
\hline & $2+$ & 240 & 18.8 & $* *$ & 37.9 & & 22.9 & & 20.4 & \\
\hline \multicolumn{11}{|l|}{ Total Long-Term Conditions } \\
\hline & 0 & 36 & 16.7 & - & 47.2 & - & 16.7 & - & 19.4 & - \\
\hline & 1 & 46 & 17.4 & & 50 & & 21.7 & & 10.9 & \\
\hline & $2+$ & 264 & 15.5 & & 40.9 & & 24.2 & & 19.3 & \\
\hline \multicolumn{11}{|l|}{ Disability Type } \\
\hline Sight, hearing, speech & & 132 & 12.12 & & 41.7 & & 25 & & 21 & \\
\hline Physical & & 243 & 18.1 & & 39.1 & & 21.8 & & 23 & \\
\hline Intellectual & & 31 & 19.4 & & 29 & $*$ & 22.6 & & 29 & \\
\hline Psychological & & 97 & 15.5 & & 27.8 & $* * *$ & 33 & $* *$ & 23.7 & \\
\hline $\begin{array}{l}\text { Head injury, stroke or brain } \\
\text { damage }\end{array}$ & & 30 & 23.3 & & 26.7 & $* *$ & 23.3 & & 26.7 & \\
\hline Other Disability & & 206 & 17 & & 42.2 & & 22.3 & & 17.9 & \\
\hline All Persons 50+ Experiencing a Barrier & & 346 & $15.9(12,19)$ & & $42.8(38,48)$ & & $23.1(19$, & 27) & $18.2(14,2$ & 22) \\
\hline
\end{tabular}

Notes: () $95 \%$ C.I.; $* * * p<0.01 * * p<0.05 * p<0.1$ for a Wald test of difference in proportions; - comparison case for test of proportions 
Table 4: Point of Care of Barrier Experienced - Multiple Disabilities, Multiple Long-Term Health Conditions and Disability Type.

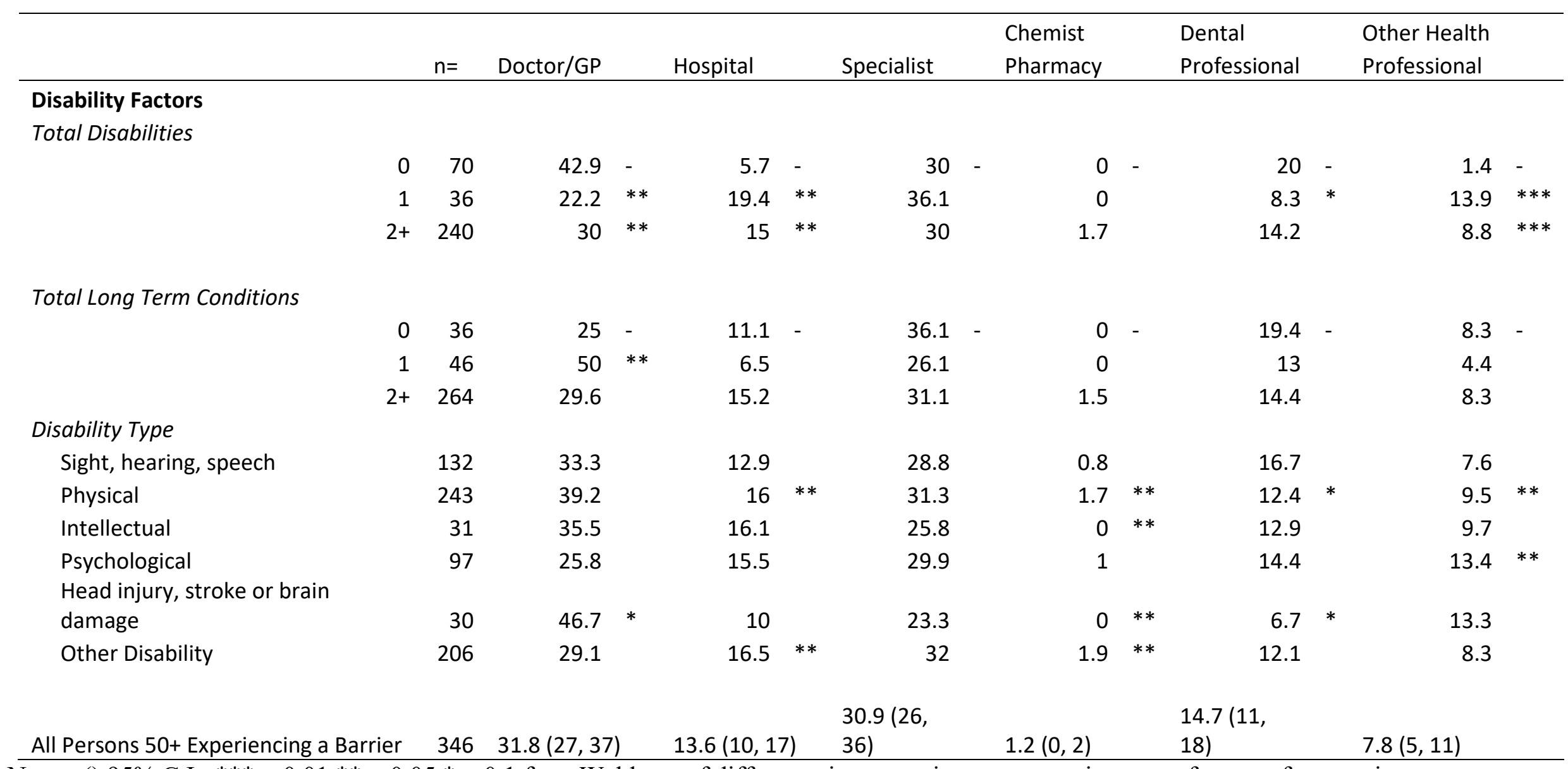

Notes: () $95 \%$ C.I.; $* * * p<0.01 * * \mathrm{p}<0.05 * \mathrm{p}<0.1$ for a Wald test of difference in proportions; - comparison case for test of proportions 
Table 5: Health Care System Experiences and Barriers to Care.

\begin{tabular}{|c|c|c|c|}
\hline & \multicolumn{3}{|c|}{ Health Care Barrier } \\
\hline & No & Yes & \\
\hline \multicolumn{4}{|l|}{$\begin{array}{l}\text { Have Trust in Health Care } \\
\text { System }\end{array}$} \\
\hline Strongly agree & 23.7 & 10.1 & $* * *$ \\
\hline Somewhat agree & 46.2 & 31.5 & $* * *$ \\
\hline Neither agree nor disagree & 13.1 & 14.4 & \\
\hline Somewhat disagree & 11.7 & 24.6 & $* * *$ \\
\hline Strongly disagree & 5.4 & 19.4 & $* * *$ \\
\hline \multicolumn{4}{|c|}{ Discriminated/Treated Unfairly in Health Care Setting } \\
\hline Yes & 1.6 & 10.4 & $* * *$ \\
\hline No & 98.4 & 89.6 & $* * *$ \\
\hline $\mathrm{n}=$ & 5666 & 346 & \\
\hline
\end{tabular}




\section{University Library}

\section{- M M N E R VA A gateway to Melbourne's research publications}

Minerva Access is the Institutional Repository of The University of Melbourne

Author/s:

Temple, JB;Williams, R

Title:

Multiple health conditions and barriers to healthcare among older Australians: prevalence, reasons and types of barriers

Date:

2018-01-01

Citation:

Temple, J. B. \& Williams, R. (2018). Multiple health conditions and barriers to healthcare among older Australians: prevalence, reasons and types of barriers. AUSTRALIAN JOURNAL OF PRIMARY HEALTH, 24 (1), pp.82-89. https://doi.org/10.1071/PY17038.

Persistent Link:

http://hdl.handle.net/11343/253841 